\title{
Adverse effects of perinatal nicotine exposure on reproductive outcomes
}

\author{
Michael K Wong, Nicole G Barra, Nadia Alfaidy, Daniel B Hardy and Alison C Holloway ${ }^{2}$ \\ Departments of Obstetrics and Gynecology, Physiology and Pharmacology, Children's Health Research Institute, \\ University of Western Ontario, London, Ontario, Canada, ${ }^{1}$ University of Grenoble-Alpes, 38000; INSERM U 1036, \\ Grenoble, France; iRTSV-Biology of Cancer and Infection, Grenoble, France and ${ }^{2}$ Department of Obstetrics and \\ Gynecology, McMaster University, RM HSC-3N52, 1280 Main Street West, Hamilton, Ontario, Canada L8S 4K1
}

Correspondence should be addressed to A C Holloway; Email: hollow@mcmaster.ca

\begin{abstract}
Nicotine exposure during pregnancy through cigarette smoking, nicotine replacement therapies or e-cigarette use continues to be a widespread public health problem, impacting both fetal and postnatal health. Yet, at this time, there remains limited data regarding the safety and efficacy in using these nicotine products during pregnancy. Notably, reports assessing the effect of nicotine exposure on postnatal health outcomes in humans, including reproductive health, are severely lacking. Our current understanding regarding the consequences of nicotine exposure during pregnancy is limited to a few animal studies, which do not comprehensively address the underlying cellular mechanisms involved. This paper aims to critically review the current knowledge from human and animal studies regarding the direct and indirect effects (e.g. obesity) of maternal nicotine exposure, regardless of its source, on reproductive outcomes in pregnancy and postnatal life. Furthermore, this review highlights several key cellular mechanisms involved in these adverse reproductive deficits including oxidative stress, inflammation, and endoplasmic reticulum (ER) stress. By understanding the interplay of the cellular mechanisms involved, further strategies could be developed to prevent the reproductive abnormalities resulting from exposure to nicotine in utero and influence informed clinical guidelines for pregnant women.

Reproduction (2015) 150 R185-R193
\end{abstract}

\section{Introduction}

Despite increased awareness of its detrimental effects, $\sim 10-23 \%$ of pregnant women continue to smoke worldwide, with rates higher than $50 \%$ in some communities (i.e., Northern Territories in Canada) (Tong et al. 2013, Cui et al. 2014). Among women who attempt to quit smoking during pregnancy, it is reported that only half will successfully abstain; the steep rates of relapse are partly attributable to the highly addictive nature of nicotine in cigarettes (Tong et al. 2013, Orton et al. 2014). However, maternal exposure to nicotine during pregnancy is not only restricted to cigarette smoking. Various nicotine-based pharmacotherapies for smoking cessation have been developed (i.e., nicotine replacement therapy (NRT)) and their usage have been considered beneficial for those struggling with heavy dependence (Myung et al. 2012). Non-combustible smoking alternatives containing nicotine (i.e., e-cigarettes) have also increased in popularity within recent years, especially among adults of reproductive age (Carroll Chapman \& Wu 2014). The effects of maternal nicotine exposure alone have been long overlooked in comparison to the health risks of tobacco smoking; however, there is currently insufficient evidence to verify the safety and efficacy of using these nicotine-containing products during pregnancy (Coleman et al. 2011, Coleman et al. 2012a, De Long et al. 2014). In fact, there is increasing evidence suggesting that maternal exposure to nicotine alone can lead to many deleterious consequences in the fetus, necessitating a more comprehensive evaluation of the long-term health effects on the offspring (Bruin et al. 2010). Alarmingly, a recent survey reported that $47 \%$ of obstetricians/gynecologists inconsistently screen their pregnant patients for exposure to these non-combustible tobacco products, and only $5 \%$ felt fully informed of the potential side effects (England et al. 2014). Therefore, this paper aims to critically review the current knowledge available on the effects of maternal nicotine exposure from recent human and animal studies. We are specifically interested in investigating the long-term reproductive health outcomes of offspring exposed to nicotine in utero. Furthermore, we will review some of the major cellular mechanisms involved, including oxidative stress, inflammation, and endoplasmic 
reticulum (ER) stress, which are suggested to underlie nicotine-induced impairments in pregnancy and reproductive organ function.

\section{Pharmacology of nicotine}

The use of nicotine during pregnancy is especially concerning because it may directly impact fetal organ development. Nicotine can easily traverse membrane barriers due to its lipophilic nature and activate nicotinic acetylcholine receptors (nAChRs) (Langley 1905, Henderson \& Lester 2015). Endogenous agonists such as acetylcholine normally bind nAChRs to regulate downstream cellular and physiological responses; however, exogenous agents like nicotine can compete for the binding sites and exert alternative, and potentially pathological, effects (Albuquerque et al. 2009).

Whole body nicotine distribution is rapid, occurring within seconds to minutes from exposure, with the highest affinities in the brain, lung, liver, kidney, spleen, and skeletal muscle (Breese et al. 1997, Benowitz et al. 2009). Nicotine also accumulates in breast milk, placental tissue, amniotic fluid, and fetal blood (Luck \& Nau 1984, Dahlstrom et al. 1990), leading to significant fetal and neonatal exposure. Research in animal models have clearly demonstrated that fetal and neonatal exposure to nicotine results in a wide range of short- and long-term health consequences for the offspring, including deficits in postnatal reproductive function (Bruin et al. 2010, Behl et al. 2013).

\section{Adverse effects of nicotine exposure during pregnancy on reproductive outcomes}

\section{Pregnancy}

There is no doubt that maternal smoking is associated with numerous adverse pregnancy outcomes, including an increased risk of spontaneous abortion, preterm birth, stillbirth, fetal growth restriction, and low birthweight (U.S. Department of Health and Human Services 2014). Studies on the effects of NRT use in human pregnancies, however, have generally reported fewer effects. A 2012 Cochrane review analyzing six randomized controlled trials of NRT use during pregnancy did not report any significant differences in rates of stillbirth, preterm labor, or low birthweight, although adherence in these studies were admittedly low (Coleman et al. 2012b). However, it is important to note that NRT use did not improve prolonged abstinence from smoking in mothers compared to placebo groups (Coleman et al. 2012a), suggesting that the doses provided may not have been sufficient to aid with smoking cessation and/or induce any changes in pregnancy or neonatal outcomes. Interestingly, another study found that the simultaneous use of more than one NRT product during pregnancy, which resulted in a higher dose of nicotine, was associated with a mild decrease in birthweight in human offspring; this indicates that higher nicotine doses may indeed carry some risks for the offspring (Lassen et al. 2010). This finding was consistent with animal studies demonstrating that nicotine exposure during pregnancy leads to significant reductions in birthweight (Holloway et al. 2005, Gruslin et al. 2009, Wang et al. 2009). Because e-cigarette use can lead to comparable nicotine levels as tobacco smoking (Dawkins \& Corcoran 2014, Etter 2014), it is possible that exposure to nicotine alone, via the use of e-cigarettes, may also lead to adverse pregnancy outcomes (Table 1).

\section{Postnatal health outcomes}

In general, fewer studies have examined the postnatal reproductive outcomes in maternal smoke-exposed offspring. In humans, prenatal exposure to cigarette smoke is associated with various reproductive health impairments in both male and female offspring (Hakonsen et al. 2014). Specifically, maternal cigarette smoking was found to lead to impaired semen quality in men and decreased fecundability in women (Hakonsen et al. 2014). These reproductive impairments may be attributed to aberrant fetal gonadal development (Mamsen et al. 2010) and/or impaired postnatal gonadal function, such as deficits in gonadal steroidogenesis (Hakonsen et al. 2014). To date, there are no human studies examining the reproductive outcomes in children exposed to NRTs in utero. Studies in animal models have identified that prenatal exposure to nicotine alone can result in increased germ cell depletion and altered steroidogenesis in male offspring (Lagunov et al. 2011, Paccola et al. 2014) and increased ovarian cell apoptosis, altered steroidogenesis, and impaired fertility in female offspring (Holloway et al. 2006, Petrik et al. 2009).

Although these impairments in postnatal reproductive health following nicotine exposure may be due to direct effects on gonad development and/or function, the possibility exists that nicotine may also indirectly affect reproductive health via changes in metabolic homeostasis. For example, obesity and type 2 diabetes mellitus (DM) have been strongly associated with detrimental reproductive outcomes, including decreased fertility, impaired sex hormone levels, and reduced sperm quality in human and animal studies (Jangir \& Jain 2014, Kawwass et al. 2015). Interestingly, prenatal nicotine exposure leads to an increased risk of postnatal obesity and DM in animal studies (Behl et al. 2013), raising the possibility that nicotine-induced obesity and/or DM may contribute to the reproductive health deficits in nicotineexposed offspring. However, it is important to note that currently none of the randomized controlled trials of NRT use during pregnancy have investigated the effects of nicotine exposure during fetal life on either metabolic or reproductive outcomes in the offspring. Given that the 
Table 1 Summary of studies investigating the adverse effects of nicotine exposure on general pregnancy and reproductive health outcomes.

\begin{tabular}{l} 
Main effects \\
\hline General pregnancy outcomes \\
No significant differences in rates of \\
miscarriage, stillbirth, preterm labor, \\
or low birthweight in mothers \\
exposed to NRTs \\
No significant differences in \\
birthweight between different NRT \\
types/duration of use. Simultaneous \\
use of more than one NRT product \\
associated with low birthweight \\
(nonsignificant) \\
Low birthweight. \\
\\
Placental outcomes \\
$\downarrow$ interstitial trophoblast invasion, \\
$\uparrow$ placenta hypoxia, and $\downarrow$ labyrinth \\
vascularization in E15 placentas \\
$\downarrow$ Trophoblast migration, invasion, and \\
differentiation \\
$\downarrow$ placental volume blood flow at \\
E155. $\uparrow$ syncytiotrophoblast \\
sprouting and villous \\
cytotrophoblast islands at E160 \\
NA
\end{tabular}

$\uparrow$ placental hypoxia and amino acid starvation. Impaired disulfide bond formation in E15 placentas $\downarrow$ cell proliferation.

Male gonadal outcomes

Spermatid retention and degeneration, tubular vacuolation, germ cell depletion, and hypospermia in 7-week-olds

Low birthweight. Leydig hypertrophy and $\uparrow$ testosterone levels in 90-day-olds (7.5-week-olds) $\downarrow$ testicular enzyme activity, plasma and intratesticular testosterone levels, plasma gonadotropin levels, sperm count, and spermatogenesis in 7-month-olds

$\downarrow$ testosterone, weights of testes, epididymis, seminal vesicles, Leydig cell number, disrupted spermatogenesis, and $\uparrow$ interstitial spaces Female gonadal

$\uparrow$ time to pregnancy, altered steroidogenesis ( $\uparrow$ progesterone and $\downarrow$ estrogen:progesterone) in 6-month-olds

$\downarrow$ granulosa cell proliferation and ovarian vascularization and $\uparrow$ ovarian cell apoptosis in

26-week-olds

$\downarrow$ cell survival with $6 \mathrm{mM}$ nicotine. Morphological damage with $10 \mathrm{mM}$ nicotine

$\uparrow$ cell death with $10 \mathrm{mM}$ smokeless tobacco nicotine

$\downarrow$ ovarian weight and number of active corpora lutea. $\uparrow$ Number of atretic follicles and endometrial degeneration
Organism (dose; length of exposure; Involvement of oxidative stress,

method) inflammation, and/or ER stress

Reference

Human (various NRT doses:

randomized control trials)

Human (various NRT doses;

self-reported telephone interviews)

Coleman et al. $(2012 a, b)$

Lassen et al. (2010)

Rat (1 mg/kg per day; 2 weeks pre-preg until weaning; s.c. inj)

Rat (1 mg/kg per day; E8 until E15,

E18, or E21; s.c. inj)

Rat (1 mg/kg per day; 2 weeks pre-preg -

until E15; s.c. inj)

Rcho- 1 cells ( $1 \mathrm{nM}-1 \mathrm{mM})$

Macaques ( $2 \mathrm{mg} / \mathrm{kg}$ per day; E26 until Oxi E160; osmotic minipump)

Oxidative stress (antioxidant vitamin C Lo et al. (2015) ameliorated placental blood flow)

Primary placental cells $(1-100 \mu \mathrm{M}$; 30 min pre-treatment)

Inflammation (Anti-inflammatory: $\downarrow$ LPS-induced TNF production, IL1b, IL8, and IL6 expression, and NFkB activation)

Rat ( $1 \mathrm{mg} / \mathrm{kg}$ per day; 2 weeks pre-preg until E15; s.c. inj)

BeWo cells (15 $\mu \mathrm{M} ; 24-72 \mathrm{~h}$ )

ER stress ( $\uparrow$ PERK and elF2a phosphorylation, and ATF4, CHOP, and GRP78 expression)

ER stress ( $\uparrow$ GRP78 expression)

Holloway et al. (2005), Gruslin et al. (2009),

Wang et al. (2009)

Holloway et al. (2014)

Rat (1 mg/kg per day; 2 weeks pre-preg until weaning; s.c. inj)

Rat (2 mg/kg per day; E1 until weaning; osmotic minipump)

Dowling et al. (2007)

Wong et al. (2015)

Repo et al. (2014)

Lagunov et al. (2011)

Paccola et al. (2014)

Rat $(0.6 \mathrm{mg} / \mathrm{kg}$ per day; 12 weeks starting in 4-month-olds; Ip inj)

Oxidative stress ( $\uparrow$ lipid peroxidation, Jana et al. (2010) hydrogen peroxide, and hydroxyl radical generation. $\downarrow$ glutathione, antioxidants, and mitochondrial membrane potential)

Rat $(1 \mathrm{mg} / \mathrm{kg}$ per day; 8 weeks starting Oxidative stress ( $\downarrow$ antioxidant activity Mosbah et al. (2015) in 8- to 12-week-olds; Ip inj) and $\uparrow$ TBARS levels. Green tea extract ameliorated nicotineinduced damage)

Rat (1 mg/kg per day; 2 weeks pre-preg until weaning; s.c. inj)

Holloway et al. (2006)

Rat ( $1 \mathrm{mg} / \mathrm{kg}$ per day; 2 weeks pre-preg until weaning; s.c. inj)

Oxidative stress (Rosiglitazone ameliorated nicotine-induced damage)

Chinese hamster ovary cell $(0.1-10 \mathrm{mM} ; 24 \mathrm{~h})$

Oxidative stress ( $\downarrow$ glutathione levels and $\uparrow$ malondialdehyde and lactate dehydrogenase)

Chinese hamster ovary cell Oxidative stress ( $\uparrow$ 8-OH-dG levels)

Petrik et al. (2009) (1-10 mM; 24 h)

Rat $(2 \mathrm{mg} / \mathrm{kg}$ per day; 30 days starting in 70-day-olds; s.c. inj)
Yildiz et al. (1998)

Yildiz (2004)

Camargo et al. (2014) 
Table 1 Continued.

\begin{tabular}{|c|c|c|c|}
\hline Main effects & $\begin{array}{l}\text { Organism (dose; length of exposure; } \\
\text { method) }\end{array}$ & $\begin{array}{l}\text { Involvement of oxidative stress, } \\
\text { inflammation, and/or ER stress }\end{array}$ & Reference \\
\hline $\begin{array}{l}\text { Morphological anomalies in ER of } \\
\text { mouse oocytes }\end{array}$ & $\begin{array}{l}\text { Mice ( } 5 \mathrm{mg} / \mathrm{kg} \text { per day; } 30 \text { days start- } \\
\text { ing in } 4 \text { - to -5-week-olds; s.c. inj) }\end{array}$ & $\begin{array}{l}\text { ER stress (Proposed due to altered ER } \\
\text { morphology) } \\
\text { Oxidative stress ( } \uparrow \text { serum MDA levels) }\end{array}$ & Rajikin et al. (2009) \\
\hline \multicolumn{4}{|c|}{ (2) } \\
\hline Low birthweight & $\begin{array}{l}\text { Rat }(2-6 \mathrm{mg} / \mathrm{kg} \text { per day; E1 until } \\
\text { parturition; s.c. inj) }\end{array}$ & $\begin{array}{l}\text { Inflammation (Pro-inflammatory: } \\
\uparrow \text { serum levels of hs-CRP, IL6, TNFa, } \\
\text { TGFb, and nitric oxide) }\end{array}$ & $\begin{array}{l}\text { Mohsenzadeh et al. } \\
\text { (2014) }\end{array}$ \\
\hline $\begin{array}{l}\text { Perinatal nicotine exposure further } \\
\text { amplified postnatal high fat } \\
\text { diet-induced alterations in neural } \\
\text { function }\end{array}$ & $\begin{array}{l}\text { Mice }(60 \mathrm{mg} / \mathrm{kg} \text { per day; E5 until } \\
\text { weaning; osmotic minipump) }\end{array}$ & $\begin{array}{l}\text { Inflammation (Pro-inflammatory: } \uparrow \\
\text { serum IL1b) }\end{array}$ & Orellana et al. (2014) \\
\hline \multicolumn{4}{|l|}{ Embryonic } \\
\hline $\begin{array}{l}\text { Morphological anomalies, } \uparrow \text { caspase } \\
3 \text { and } \downarrow \text { BclxL expression }\end{array}$ & Mouse embryo ( $1 \mathrm{mM}$; $48 \mathrm{~h}$ exposure) & $\begin{array}{l}\text { Inflammation (Pro-inflammatory: } \\
\uparrow \text { TNFa and IL } 1 \text { b expression) } \\
\text { Oxidative stress ( } \uparrow \text { lipid peroxidation } \\
\quad \text { and } \downarrow \text { antioxidant activity) }\end{array}$ & Lin et al. (2014) \\
\hline
\end{tabular}

NRT, nicotine replacement therapy; s.c. inj, subcutaneous injection; Ip inj, i.p. injection; pre-preg, Pre-pregnancy; E, embryonic/gestational day; LPS, lipopolysaccharide; ER, endoplasmic reticulum; MDA, malonaldeyhde; hs-CRP, high-sensitivity C-reactive protein.

animal literature implicates impairments in offspring fertility following nicotine exposure in utero, future clinical studies investigating the long-term reproductive health outcomes of human adults exposed to nicotine alone are warranted.

With the increasing use of e-cigarettes in women of reproductive age (Carroll Chapman \& Wu 2014) and continuing uncertainties surrounding the safety of NRT use during pregnancy (De Long et al. 2014), there remains a critical need to further understand the longterm health impacts of developmental nicotine exposure. There is emerging evidence from animal studies that prenatal nicotine exposure may compromise reproductive health in the exposed offspring, yet we are only beginning to understand the cellular events that mediate these long-term consequences. The remainder of this review will focus on the underlying roles of oxidative stress, inflammation, and ER stress in nicotineinduced injury with a focus on placental development/ function and reproductive outcomes in the exposed offspring.

\section{Cellular mechanisms underlying adverse nicotine-induced reproductive health outcomes}

The role of reactive oxygen species and oxidative stress

Free radicals, such as reactive oxygen species (ROS), are generated as a natural by-product of cellular metabolism and oxidative protein folding in the mitochondria and ER. Common forms of ROS include nitric oxide (NO), superoxide $\left(\mathrm{O}_{2}^{-}\right)$, and hydrogen peroxide $\left(\mathrm{H}_{2} \mathrm{O}_{2}\right)$, which carry out important cellular functions under physiologically balanced levels (e.g., signaling/feedback, autophagy, oxygen sensing, immunity/inflammation, and cell differentiation) (Sena \& Chandel 2012). Augmented pro-oxidant ROS quantities and/or impaired antioxidant capacity alters oxidative balance and culminates in a condition known as 'oxidative stress.' Under conditions of prolonged oxidative stress, the unstable reactivity of excessive ROS can lead to free radical damage in DNA, proteins, carbohydrates, and lipids, and eventually, mitochondrial-mediated apoptosis and cell death (Cao \& Kaufman 2014, Chaudhari et al. 2014). Increased oxidative stress has been demonstrated to impair placental development and function as well as cause damage to oocytes, sperm, and embryos (Agarwal et al. 2008, Herrera et al. 2014, Holloway et al. 2014), thus it is thought to underlie many aspects of impaired reproductive health (Agarwal et al. 2012, Agarwal et al. 2014, Dai et al. 2015).

In animal models, maternal administration of nicotine adversely affects placental development and function (Holloway et al. 2014, Lo et al. 2015). Although maternal tobacco use has been shown to increase markers of oxidative stress in the placenta (Sbrana et al. 2011), in vivo and in vitro studies have failed to find evidence of oxidative damage or increased ROS production in trophoblast cells following nicotine administration (Holloway et al. 2014, Repo et al. 2014, Lo et al. 2015). Interestingly, placentas from nicotinetreated animals exhibit evidence of hypoxia, which has been demonstrated to increase ROS production (Herrera et al. 2014). Consistent with this observation, nicotine treatment decreased local and circulating endocrine gland-derived vascular endothelial growth factor (EGVEGF) in vivo and in vitro, a key placental angiogenic factor (Brouillet et al. 2012, Holloway et al. 2014). Disruption in the establishment of feto-maternal circulation may lead to increased hypoxia and oxidative damage in the placenta (Holloway et al. 2014). Moreover, some of the nicotine-induced deficits in placental function can be ameliorated by coadministration with an antioxidant (e.g., vitamin C) (Lo et al. 2015). Taken together, these results suggest 
that subtle changes in the placental redox balance may underlie nicotine-induced deficits in placental development and function.

There is considerable evidence from animal studies that perinatal exposure to nicotine results in oxidative stress and/or decreased antioxidant potential in the offspring (Bruin et al. 2008, Xiao et al. 2011, Conceicao et al. 2015), suggesting that increased oxidative stress may be a potential mechanism underlying deleterious nicotine-induced reproductive outcomes. Indeed, adult animals exposed to nicotine exhibited increased ROS production and oxidative damage in the testes, which was associated with testicular damage and decreased sperm counts (Jana et al. 2010, Mosbah et al. 2015). Interestingly, the testicular pathology caused by nicotine exposure in the adult animals (e.g., degeneration of seminiferous tubules, germ cell exfoliation, loss of Leydig cells, and disrupted spermatogenesis) (Jana et al. 2010, Mosbah et al. 2015) are remarkably similar to the histological results in the testes of male offspring who were exposed to nicotine in utero (Lagunov et al. 2011, Paccola et al. 2014), suggesting a common underlying mechanism. The relationship between nicotine, oxidative stress, and ovarian physiology has been less well studied, although nicotine has been shown to cause oxidative stress in Chinese Hamster Ovary cells (Yildiz et al. 1998, Yildiz 2004). Importantly, oxidative stress is associated with increased ovarian cell apoptosis and follicle loss - outcomes that have been similarly observed in rats exposed to nicotine in adulthood (Camargo et al. 2014) and fetal life (Petrik et al. 2009). Collectively, these findings suggest that nicotine-induced oxidative stress may be an important, and potentially modifiable, pathway leading to impaired reproductive health in the offspring.

\section{The role of inflammation}

Inflammation is a complex physiological response involving the influx of activated leukocytes and increased production of pro-inflammatory cytokines (i.e., tumor necrosis factor alpha (TNF $\alpha$ ), interleukin 1 beta (IL1 $\beta$ ) and interleukin 6 (IL6)), chemokines, and growth factors. Acute inflammatory activation is necessary in responding to infectious or environmental insults, yet, prolonged inflammation may lead to many potential reproductive complications including impaired placental development/function and infertility (Weiss et al. 2009, Schmatz et al. 2010, Christiansen 2013, Bachir \& Jarvi 2014).

Cytokines produced by cells in the feto-maternal interface play a key role in the regulation of placental development (i.e., trophoblast proliferation, migration, and invasion) and function (i.e., placental hormone secretion) (Bowen et al. 2002). Nicotine treatment of placental cells in vitro reduced lipopolysaccharide (LPS)induced production of the cytokines IL1 $\beta$ and IL6 (Dowling et al. 2007), which play an important role in trophoblast invasion and migration (Jovanovic \& Vicovac 2009, Prutsch et al. 2012). This data suggests that the adverse effects of maternal smoking on pregnancy outcomes might be due in part to the direct effects of nicotine on the main processes of placental development; however, whether inflammatory responses play a critical role in the nicotine-induced deficits in placental development and function have yet to be fully verified.

Although there is considerable evidence that nicotine exposure in adults results in anti-inflammatory responses in a variety of tissues (Gallowitsch-Puerta \& Tracey 2005), fetal exposure to nicotine has been associated with increased inflammation in the offspring. Rodents exposed to nicotine in utero had significantly increased circulating serum pro-inflammatory cytokines (e.g., IL1 $\beta$, IL6, and TNF $\alpha$ ) throughout early development and adulthood (Mohsenzadeh et al. 2014, Orellana et al. 2014). Similarly, embryos exposed to nicotine had increased gene expression of TNF $\alpha$ and IL1 $\beta$ (Lin et al. 2014). Importantly, these cytokines play key roles in germ cell survival and gonadal steroidogenesis (Bornstein et al. 2004, Perez et al. 2013, Field et al. 2014). As fetal exposure to nicotine in rodents has been demonstrated to cause germ cell loss and altered steroidogenesis (Holloway et al. 2006, Petrik et al. 2009, Lagunov et al. 2011, Paccola et al. 2014), it is biologically plausible that these effects may be mediated by an altered inflammatory response, although this has yet to be experimentally determined.

\section{The role of ER stress and the unfolded protein response}

The ER is the essential organelle responsible for protein synthesis, folding, and secretion, lipid biosynthesis, and calcium homeostasis (Braakman \& Bulleid 2011). Any perturbation of ER function and homeostasis resulting in the lumenal accumulation of misfolded or unfolded proteins is known as 'ER stress.' The unfolded protein response (UPR) initially seeks to restore ER homeostasis by attenuating the global rate of incoming protein translation, while paradoxically increasing the expression of genes involved in improving protein folding capacity. However, in the presence of prolonged ER stress, apoptosis is initiated (Chambers \& Marciniak 2014, Kawakami et al. 2014).

The role of ER stress in adverse nicotine-induced reproductive outcomes has not been studied extensively. The placenta is particularly susceptible to ER stress due to its high protein secretory activity, and augmented ER stress has been demonstrated to be associated with adverse placental development and fetal growth restriction (Yung et al. 2012, Kawakami et al. 2014, Yang et al. 2015). Interestingly, similar placental and fetal outcomes were reported in animal models of nicotine exposure during pregnancy (Holloway et al. 2005, Holloway et al. 2014, Gruslin et al. 2009). Indeed, nicotine administration during pregnancy increased placental ER stress 


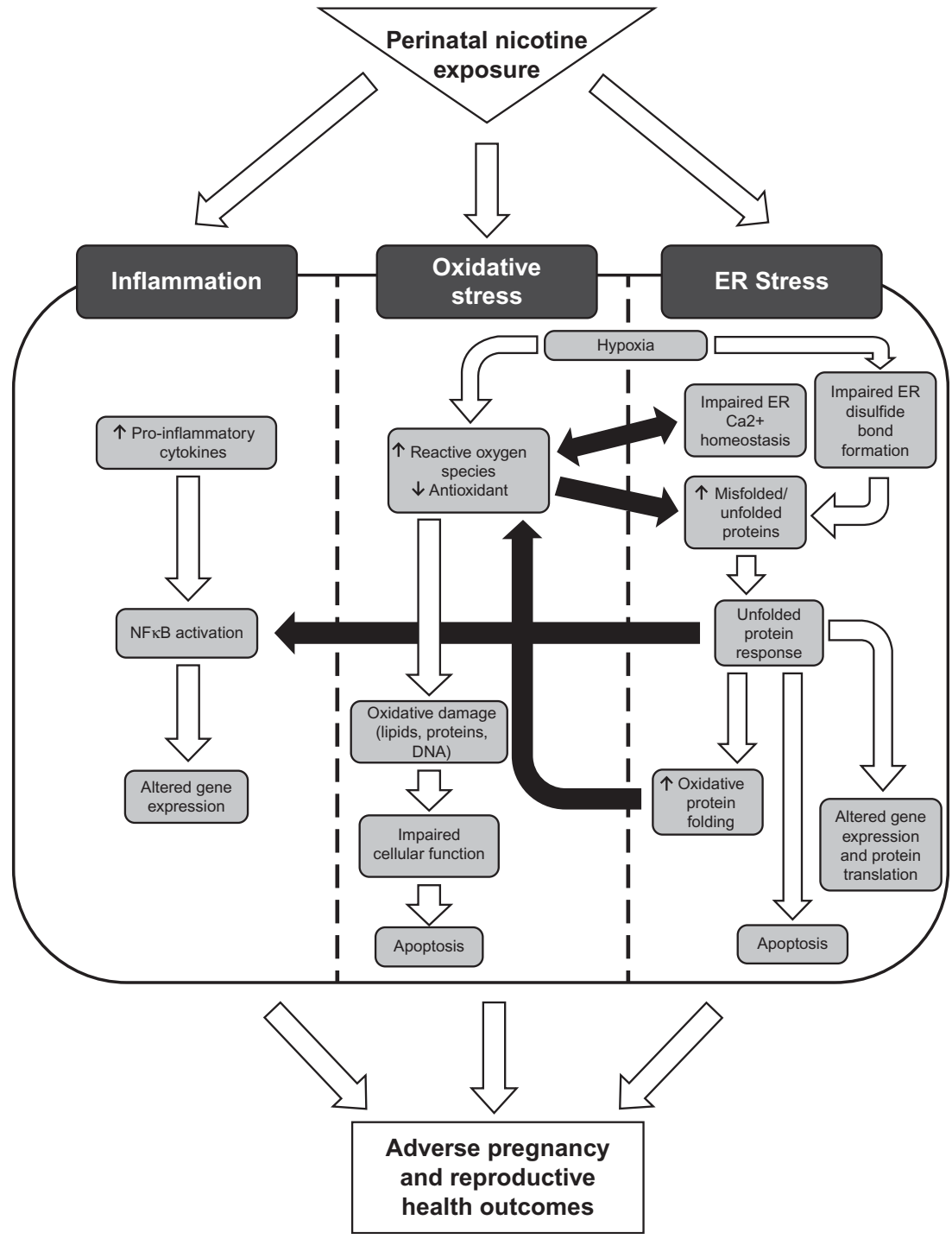

Figure 1 Proposed mechanisms by which prenatal nicotine exposure can adversely influence pregnancy (i.e., effects on placenta) and postnatal reproductive health outcomes (i.e., effects on gonadal development and function). White arrows indicate the normal pathway within a specific mechanism, whereas black arrows indicate interconnected pathways between the mechanisms. resulting in the activation of the UPR at embryonic day 15 (Wong et al. 2015). It is possible that this is due to a direct effect of nicotine on the placenta, as cultured human trophoblast cells treated with nicotine had an increased expression of some ER stress markers (Repo et al. 2014). Alternatively, nicotine could be acting indirectly, as maternal nicotine exposure is known to induce vasoconstriction in placental vasculature (Pastrakuljic et al. 1999, Machaalani et al. 2014), decrease placental blood flow (Lo et al. 2015), and decrease trophoblast invasion leading to a delay in the establishment of the fetomaternal circulation (Holloway et al. 2014). The ensuing reduction in oxygen supply may cause placental hypoxia, which is also a trigger for ER stress (Koritzinsky et al. 2013, Holloway et al. 2014, Wong et al. 2015).

To date, there is no evidence directly linking prenatal nicotine exposure to ER stress in male or female reproductive organs; however, several indirect lines of evidence suggest that ER stress may be a cellular mechanism underlying reproductive deficits in nicotineexposed offspring. Firstly, ER stress has been shown to play a key role in ovarian cell apoptosis and follicular atresia (Yang et al. 2015), a phenotype similarly observed in nicotine-exposed offspring (Petrik et al. 2009). Secondly, nicotine exposure causes morphological changes in the ER of adult mouse oocytes (Rajikin et al. 2009); ultrastructural changes in the ER have also been documented in response to ER stress (Schonthal 2012). Finally, adult male mice exposed to cigarette smoke had altered protein processing in the epididymis (Zhu et al. 2013) - an observation consistent with altered sperm maturation seen in nicotine-exposed rat offspring (Lagunov et al. 2011). Taken together, these findings suggest the possibility that fetal exposure to nicotine may increase ER stress in the ovary and testes potentially leading to reproductive deficits in postnatal life. For more detail on general pregnancy outcomes and cellular mechanisms involved, please refer to Table 1. 


\section{Conclusion}

In summary, we have presented evidence from a wide collection of animal and cell culture studies proposing the deleterious impact of prenatal nicotine exposure on pregnancy outcomes and the reproductive health of both male and female offspring. The deleterious effects of nicotine in the placenta and reproductive organs may be mediated through, but not limited to, the augmentation of oxidative stress, inflammation, and ER stress. Importantly, current research suggests that the functional involvement of these three mechanisms are very often inseparable (Fig. 1) (Chaudhari et al. 2014). For example, oxidative stress and ER stress are often tightly linked, and the activation of ER stress has been shown to trigger inflammatory pathways (Chaudhari et al. 2014). However, the degree to which each mechanism may differentially contribute to adverse pregnancy and reproductive outcomes is currently not well understood. Therefore, future research investigating the mechanistic underpinnings of maternal nicotine exposure must take an integrative approach to understand the relative involvements of oxidative stress, inflammation, and ER stress. Moreover, despite how evidence from both in vitro and animal studies have demonstrated that early life exposure to nicotine may cause impaired reproductive health of the offspring, these outcomes have not been well studied in humans. Given that there is still considerable controversy surrounding the long-term effects of NRT use during pregnancy as it relates to both conventional NRT (i.e. gum, patches, and spray) and emerging forms of nicotine delivery (i.e. e-cigarettes) (De Long et al. 2014), further studies of the long-term health outcomes of nicotine exposure, including reproductive outcomes, are urgently needed.

\section{Declaration of Interest}

There is no conflict of interest that could be perceived as prejudicing the impartiality of this review.

\section{Funding}

This work was supported by the Canadian Institutes for Health Research (MOP86474 to A C Holloway and MOP 111011 to D B Hardy). M K Wong is a recipient of an Ontario Graduate Scholarship (OGS), and N G Barra is a recipient of a Whaley and Molly Towell Perinatal Research Foundation Postdoctoral Fellowship.

\section{References}

Agarwal A, Gupta S, Sekhon L \& Shah R 2008 Redox considerations in female reproductive function and assisted reproduction: from molecular mechanisms to health implications. Antioxidants \& Redox Signaling 10 1375-1403. (doi:10.1089/ars.2007.1964)
Agarwal A, Aponte-Mellado A, Premkumar BJ, Shaman A \& Gupta S 2012 The effects of oxidative stress on female reproduction: a review. Reproductive Biology and Endocrinology 10 49. (doi:10.1186/14777827-10-49)

Agarwal A, Virk G, Ong C \& du Plessis SS 2014 Effect of oxidative stress on male reproduction. World Journal of Men's Health 32 1-17. (doi:10.5534/wjmh.2014.32.1.1)

Albuquerque EX, Pereira EF, Alkondon M \& Rogers SW 2009 Mammalian nicotinic acetylcholine receptors: from structure to function. Physiological Reviews 89 73-120. (doi:10.1152/physrev.00015.2008)

Bachir BG \& Jarvi K 2014 Infectious, inflammatory, and immunologic conditions resulting in male infertility. Urologic Clinics of North America 41 67-81. (doi:10.1016/j.ucl.2013.08.008)

BehI M, Rao D, Aagaard K, Davidson TL, Levin ED, Slotkin TA, Srinivasan S, Wallinga D, White MF, Walker VR et al. 2013 Evaluation of the association between maternal smoking, childhood obesity, and metabolic disorders: a national toxicology program workshop review. Environmental Health Perspectives 121 170-180. (doi:10.1289/ehp. 1205404)

Benowitz NL, Hukkanen J \& Jacob P III 2009 Nicotine chemistry, metabolism, kinetics and biomarkers. Handbook of Experimental Pharmacology 192 29-60. (doi:10.1007/978-3-540-69248-5_2)

Bornstein SR, Rutkowski H \& Vrezas I 2004 Cytokines and steroidogenesis. Molecular and Cellular Endocrinology 215 135-141. (doi:10.1016/ j.mce.2003.11.022)

Bowen JM, Chamley L, Keelan JA \& Mitchell MD 2002 Cytokines of the placenta and extra-placental membranes: roles and regulation during human pregnancy and parturition. Placenta 23 257-273. (doi:10.1053/ plac.2001.0782)

Braakman I \& Bulleid NJ 2011 Protein folding and modification in the mammalian endoplasmic reticulum. Annual Review of Biochemistry $\mathbf{8 0}$ 71-99. (doi:10.1146/annurev-biochem-062209-093836)

Breese CR, Marks MJ, Logel J, Adams CE, Sullivan B, Collins AC \& Leonard S 1997 Effect of smoking history on [3H]nicotine binding in human postmortem brain. Journal of Pharmacology and Experimental Therapeutics 282 7-13.

Brouillet S, Hoffmann P, Feige JJ \& Alfaidy N 2012 EG-VEGF: a key endocrine factor in placental development. Trends in Endocrinology and Metabolism 23 501-508. (doi:10.1016/j.tem.2012.05.006)

Bruin JE, Petre MA, Lehman MA, Raha S, Gerstein HC, Morrison KM \& Holloway AC 2008 Maternal nicotine exposure increases oxidative stress in the offspring. Free Radical Biology \& Medicine 44 1919-1925. (doi:10.1016/j.freeradbiomed.2008.02.010)

Bruin JE, Gerstein HC \& Holloway AC 2010 Long-term consequences of fetal and neonatal nicotine exposure: a critical review. Toxicological Sciences 116 364-374. (doi:10.1093/toxsci/kfq103)

Camargo IC, Leite GA, Pinto T \& Ribeiro-Paes JT 2014 Histopathologycal findings in the ovaries and uterus of albino female rats promoted by co-administration of synthetic steroids and nicotine. Experimental and Toxicologic Pathology 66 195-202. (doi:10.1016/j.etp.2014.01.005)

Cao SS \& Kaufman RJ 2014 Endoplasmic reticulum stress and oxidative stress in cell fate decision and human disease. Antioxidants \& Redox Signaling 21 396-413. (doi:10.1089/ars.2014.5851)

Carroll Chapman SL \& Wu LT 2014 E-cigarette prevalence and correlates of use among adolescents versus adults: a review and comparison. Journal of Psychiatric Research 54 43-54. (doi:10.1016/j.jpsychires. 2014.03.005)

Chambers JE \& Marciniak SJ 2014 Cellular mechanisms of endoplasmic reticulum stress signaling in health and disease. 2. Protein misfolding and ER stress. American Journal of Physiology. Cell Physiology 307 C657-C670. (doi:10.1152/ajpcell.00183.2014)

Chaudhari N, Talwar P, Parimisetty A, Lefebvre d'Hellencourt C \& Ravanan P 2014 A molecular web: endoplasmic reticulum stress, inflammation, and oxidative stress. Frontiers in Cellular Neuroscience $\mathbf{8}$ 213. (doi:10.3389/fncel.2014.00213)

Christiansen OB 2013 Reproductive immunology. Molecular Immunology 55 8-15. (doi:10.1016/j.molimm.2012.08.025)

Coleman T, Chamberlain C, Cooper S \& Leonardi-Bee J 2011 Efficacy and safety of nicotine replacement therapy for smoking cessation in pregnancy: systematic review and meta-analysis. Addiction 106 52-61. (doi:10.1111/j.1360-0443.2010.03179.x) 
Coleman T, Cooper S, Thornton JG, Grainge MJ, Watts K, Britton J, Lewis S, Smoking N \& Pregnancy Trial T 2012a A randomized trial of nicotinereplacement therapy patches in pregnancy. New England Journal of Medicine 366 808-818. (doi:10.1056/NEJMoa1109582)

Coleman T, Chamberlain C, Davey MA, Cooper SE \& Leonardi-Bee J 2012b Pharmacological interventions for promoting smoking cessation during pregnancy. Cochrane Database of Systematic Reviews 9 CD010078. (doi:10.1002/14651858)

Conceicao EP, Peixoto-Silva N, Pinheiro CR, Oliveira E, Moura EG \& Lisboa PC 2015 Maternal nicotine exposure leads to higher liver oxidative stress and steatosis in adult rat offspring. Food and Chemical Toxicology 78C 52-59. (doi:10.1016/j.fct.2015.01.025)

Cui Y, Shooshtari S, Forget EL, Clara I \& Cheung KF 2014 Smoking during pregnancy: findings from the 2009-2010 Canadian Community Health Survey. PLOS ONE 9 e84640. (doi:10.1371/journal.pone.0084640)

Dahlstrom A, Lundell B, Curvall M \& Thapper L 1990 Nicotine and cotinine concentrations in the nursing mother and her infant. Acta Paediatrica Scandinavica 79 142-147. (doi:10.1111/j.1651-2227.1990.tb11430.x)

Dai JB, Wang ZX \& Qiao ZD 2015 The hazardous effects of tobacco smoking on male fertility. Asian Journal of Andrology. In press. (doi:10. 4103/1008-682X.150847)

Dawkins L \& Corcoran O 2014 Acute electronic cigarette use: nicotine delivery and subjective effects in regular users. Psychopharmacology 231 401-407. (doi:10.1007/s00213-013-3249-8)

De Long NE, Barra NG, Hardy DB \& Holloway AC 2014 Is it safe to use smoking cessation therapeutics during pregnancy? Expert Opinion on Drug Safety 13 1721-1731. (doi:10.1517/14740338.2014.973846)

Dowling O, Rochelson B, Way K, Al-Abed Y \& Metz CN 2007 Nicotine inhibits cytokine production by placenta cells via NFkappaB: potential role in pregnancy-induced hypertension. Molecular Medicine $\mathbf{1 3}$ 576-583. (doi:10.2119/2007-00067.Dowling)

England LJ, Anderson BL, Tong VT, Mahoney J, Coleman-Cowger VH, Melstrom P \& Schulkin J 2014 Screening practices and attitudes of obstetricians-gynecologists toward new and emerging tobacco products. American Journal of Obstetrics and Gynaecology 695 e691-e697. (doi:10.1016/j.ajog.2014.05.041)

Etter JF 2014 Levels of saliva cotinine in electronic cigarette users. Addiction 109 825-829. (doi:10.1111/add.12475)

Field SL, Dasgupta T, Cummings M \& Orsi NM 2014 Cytokines in ovarian folliculogenesis, oocyte maturation and luteinisation. Molecular Reproduction and Development 81 284-314. (doi:10.1002/mrd.22285)

Gallowitsch-Puerta M \& Tracey KJ 2005 Immunologic role of the cholinergic anti-inflammatory pathway and the nicotinic acetylcholine alpha 7 receptor. Annals of the New York Academy of Sciences 1062 209-219. (doi:10.1196/annals.1358.024)

Gruslin A, Cesta CE, Bell M, Qing Q, Petre MA \& Holloway AC 2009 Effect of nicotine exposure during pregnancy and lactation on maternal, fetal, and postnatal rat IGF-II profile. Reproductive Sciences 16 875-882. (doi:10.1177/1933719109337038)

Hakonsen LB, Ernst A \& Ramlau-Hansen CH 2014 Maternal cigarette smoking during pregnancy and reproductive health in children: a review of epidemiological studies. Asian Journal of Andrology 16 39-49. (doi:10.4103/1008-682X.122351)

Henderson BJ \& Lester HA 2015 Inside-out neuropharmacology of nicotinic drugs. Neuropharmacology 96 (Pt B) 178-193. (doi:10.1016/ j.neuropharm.2015.01.022)

Herrera EA, Krause B, Ebensperger G, Reyes RV, Casanello P, ParraCordero M \& Llanos AJ 2014 The placental pursuit for an adequate oxidant balance between the mother and the fetus. Frontiers in Pharmacology 5 149. (doi:10.3389/fphar.2014.00149)

Holloway AC, Lim GE, Petrik JJ, Foster WG, Morrison KM \& Gerstein HC 2005 Fetal and neonatal exposure to nicotine in Wistar rats results in increased beta cell apoptosis at birth and postnatal endocrine and metabolic changes associated with type 2 diabetes. Diabetologia 48 2661-2666. (doi:10.1007/s00125-005-0022-5)

Holloway AC, Kellenberger LD \& Petrik JJ 2006 Fetal and neonatal exposure to nicotine disrupts ovarian function and fertility in adult female rats. Endocrine 30 213-216. (doi:10.1385/ENDO:30:2:213)

Holloway AC, Salomon A, Soares MJ, Garnier V, Raha S, Sergent F, Nicholson CJ, Feige JJ, Benharouga M \& Alfaidy N 2014 Characterization of the adverse effects of nicotine on placental development: in vivo and in vitro studies. American Journal of Physiology. Endocrinology and Metabolism 306 E443-E456. (doi:10.1152/ajpendo. 00478.2013)

Jana K, Samanta PK \& De DK 2010 Nicotine diminishes testicular gametogenesis, steroidogenesis, and steroidogenic acute regulatory protein expression in adult albino rats: possible influence on pituitary gonadotropins and alteration of testicular antioxidant status. Toxicological Sciences 116 647-659. (doi:10.1093/toxsci/kfq149)

Jangir RN \& Jain GC 2014 Diabetes mellitus induced impairment of male reproductive functions: a review. Current Diabetes Reviews 10 147-157. (doi:10.2174/1573399810666140606111745)

Jovanovic M \& Vicovac L 2009 Interleukin-6 stimulates cell migration, invasion and integrin expression in HTR-8/SVneo cell line. Placenta 30 320-328. (doi:10.1016/j.placenta.2009.01.013)

Kawakami T, Yoshimi M, Kadota Y, Inoue M, Sato M \& Suzuki S 2014 Prolonged endoplasmic reticulum stress alters placental morphology and causes low birth weight. Toxicology and Applied Pharmacology 275 134-144. (doi:10.1016/j.taap.2013.12.008)

Kawwass JF, Summer R \& Kallen CB 2015 Direct effects of leptin and adiponectin on peripheral reproductive tissues: a critical review. Molecular Human Reproduction 21 617-632. (doi:10.1093/molehr/ gav025)

Koritzinsky M, Levitin F, van den Beucken T, Rumantir RA, Harding NJ, Chu KC, Boutros PC, Braakman I \& Wouters BG 2013 Two phases of disulfide bond formation have differing requirements for oxygen. Journal of Cell Biology 203 615-627. (doi:10.1083/jcb. 201307185)

Lagunov A, Anzar M, Sadeu JC, Khan MI, Bruin JE, Woynillowicz AK, Buhr M, Holloway AC \& Foster WG 2011 Effect of in utero and lactational nicotine exposure on the male reproductive tract in peripubertal and adult rats. Reproductive Toxicology 31 418-423. (doi:10.1016/j.reprotox.2010.12.004)

Langley JN 1905 On the reaction of cells and of nerve-endings to certain poisons, chiefly as regards the reaction of striated muscle to nicotine and to curari. Journal of Physiology 33 (4-5) 374-413. (doi:10.1113/jphysiol. 1905.sp001128)

Lassen TH, Madsen M, Skovgaard LT, Strandberg-Larsen K, Olsen J \& Andersen AM 2010 Maternal use of nicotine replacement therapy during pregnancy and offspring birthweight: a study within the Danish National Birth Cohort. Paediatric and Perinatal Epidemiology 24 272-281. (doi:10.1111/j.1365-3016.2010.01104.x)

Lin C, Yon JM, Hong JT, Lee JK, Jeong J, Baek IJ, Lee BJ, Yun YW \& Nam SY 2014 4-O-methylhonokiol inhibits serious embryo anomalies caused by nicotine via modulations of oxidative stress, apoptosis, and inflammation. Birth Defects Research. Part B, Developmental and Reproductive Toxicology 101 125-134. (doi:10.1002/bdrb.21092)

Lo JO, Schabel MC, Roberts VH, Morgan TK, Rasanen JP, Kroenke CD, Shoemaker SR, Spindel ER \& Frias AE 2015 Vitamin C supplementation ameliorates the adverse effects of nicotine on placental hemodynamics and histology in nonhuman primates. American Journal of Obstetrics and Gynaecology 370 e371-e378. (doi:10.1016/j.ajog.2014.12.042)

Luck W \& Nau H 1984 Nicotine and cotinine concentrations in serum and milk of nursing smokers. British Journal of Clinical Pharmacology $\mathbf{1 8}$ 9-15. (doi:10.1111/j.1365-2125.1984.tb05014.x)

Machaalani R, Ghazavi E, Hinton T, Waters KA \& Hennessy A 2014 Cigarette smoking during pregnancy regulates the expression of specific nicotinic acetylcholine receptor (nAChR) subunits in the human placenta. Toxicology and Applied Pharmacology 276 204-212. (doi:10.1016/j.taap.2014.02.015)

Mamsen LS, Lutterodt MC, Andersen EW, Skouby SO, Sorensen KP, Andersen CY \& Byskov AG 2010 Cigarette smoking during early pregnancy reduces the number of embryonic germ and somatic cells. Human Reproduction 25 2755-2761. (doi:10.1093/humrep/deq215)

Mohsenzadeh Y, Rahmani A, Cheraghi J, Pyrani M \& Asadollahi K 2014 Prenatal exposure to nicotine in pregnant rat increased inflammatory marker in newborn rat. Mediators of Inflammation 2014274048. (doi:10.1155/2014/274048)

Mosbah R, Yousef MI \& Mantovani A 2015 Nicotine-induced reproductive toxicity, oxidative damage, histological changes and haematotoxicity in male rats: the protective effects of green tea extract. Experimental and Toxicologic Pathology 67 253-259. (doi:10.1016/j.etp. 2015.01.001) 
Myung SK, Ju W, Jung HS, Park CH, Oh SW, Seo H, Kim H \& Korean MetaAnalysis Study G 2012 Efficacy and safety of pharmacotherapy for smoking cessation among pregnant smokers: a meta-analysis. BJOG 119 1029-1039. (doi:10.1111/j.1471-0528.2012.03408.x)

Orellana JA, Busso D, Ramirez G, Campos M, Rigotti A, Eugenin J \& von Bernhardi R 2014 Prenatal nicotine exposure enhances $C \times 43$ and Panx1 unopposed channel activity in brain cells of adult offspring mice fed a high-fat/cholesterol diet. Frontiers in Cellular Neuroscience 8403. (doi:10.3389/fncel.2014.00403)

Orton S, Bowker K, Cooper S, Naughton F, Ussher M, Pickett KE, LeonardiBee J, Sutton S, Dhalwani NN \& Coleman T 2014 Longitudinal cohort survey of women's smoking behaviour and attitudes in pregnancy: study methods and baseline data. BMJ Open 4 e004915. (doi:10.1136/ bmjopen-2014-004915)

Paccola CC, Neves FM, Cipriano I, Stumpp T \& Miraglia SM 2014 Effects of prenatal and lactation nicotine exposure on rat testicular interstitial tissue. Andrology 2 175-185. (doi:10.1111/j.2047-2927.2013. 00168.x)

Pastrakuljic A, Derewlany LO \& Koren G 1999 Maternal cocaine use and cigarette smoking in pregnancy in relation to amino acid transport and fetal growth. Placenta 20 499-512. (doi:10.1053/plac.1999.0418)

Perez CV, Theas MS, Jacobo PV, Jarazo-Dietrich S, Guazzone VA \& Lustig L 2013 Dual role of immune cells in the testis: Protective or pathogenic for germ cells? Spermatogenesis 3 e23870. (doi:10.4161/ spmg.23870)

Petrik JJ, Gerstein HC, Cesta CE, Kellenberger LD, Alfaidy N \& Holloway AC 2009 Effects of rosiglitazone on ovarian function and fertility in animals with reduced fertility following fetal and neonatal exposure to nicotine. Endocrine 36 281-290. (doi:10.1007/s12020-009-9229-4)

Prutsch N, Fock V, Haslinger P, Haider S, Fiala C, Pollheimer J \& Knofler M 2012 The role of interleukin-1beta in human trophoblast motility. Placenta 33 696-703. (doi:10.1016/j.placenta.2012.05.008)

Rajikin MH, Latif ES, Mar MR, Mat Top AG \& Mokhtar NM 2009 Deleterious effects of nicotine on the ultrastructure of oocytes: role of gamma-tocotrienol. Medical Science Monitor 15 BR378-BR383.

Repo JK, Pesonen M, Mannelli C, Vahakangas K \& Loikkanen J 2014 Exposure to ethanol and nicotine induces stress responses in human placental BeWo cells. Toxicology Letters 224 264-271. (doi:10.1016/j. toxlet.2013.10.032)

Sbrana E, Suter MA, Abramovici AR, Hawkins HK, Moss JE, Patterson L, Shope C \& Aagaard-Tillery K 2011 Maternal tobacco use is associated with increased markers of oxidative stress in the placenta. American Journal of Obstetrics and Gynaecology 246 e241-e247. (doi:10.1016/j. ajog.2011.06.023)

Schmatz M, Madan J, Marino T \& Davis J 2010 Maternal obesity: the interplay between inflammation, mother and fetus. Journal of Perinatology 30 441-446. (doi:10.1038/jp.2009.182)

Schonthal AH 2012 Endoplasmic reticulum stress: its role in disease and novel prospects for therapy. Scientifica 2012 857516. (doi:10.6064/ 2012/857516)

Sena LA \& Chandel NS 2012 Physiological roles of mitochondrial reactive oxygen species. Molecular Cell 48 158-167. (doi:10.1016/j.molcel. 2012.09.025)
Tong VT, Dietz PM, Morrow B, D'Angelo DV, Farr SL, Rockhill KM \& England LJ 2013 Trends in smoking before, during, and after pregnancy pregnancy risk assessment monitoring system, United States, 40 sites, 2000-2010. Morbidity and Mortality Weekly Report. Surveillance Summaries 62 1-19.

U.S. Department of Health and Human Services 2014, Warren GW1, Alberg AJ, Kraft AS \& Cummings KM. The Health Consequences of Smoking: 50 Years of Progress. A Report of the Surgeon General. Cancer 120 1914-1916.

Wang T, Chen M, Yan YE, Xiao FQ, Pan XL \& Wang H 2009 Growth retardation of fetal rats exposed to nicotine in utero: possible involvement of CYP1A1, CYP2E1, and P-glycoprotein. Environmental Toxicology 24 33-42. (doi:10.1002/tox.20391)

Weiss G, Goldsmith LT, Taylor RN, Bellet D \& Taylor HS 2009 Inflammation in reproductive disorders. Reproductive Sciences 16 216-229. (doi:10. 1177/1933719108330087)

Wong MK, Nicholson CJ, Holloway AC \& Hardy DB 2015 Maternal nicotine exposure leads to impaired disulfide bond formation and augmented endoplasmic reticulum stress in the rat placenta. PLOS ONE 10 e0122295. (doi:10.1371/journal.pone.0122295)

Xiao D, Huang X, Yang S \& Zhang L 2011 Antenatal nicotine induces heightened oxidative stress and vascular dysfunction in rat offspring. British Journal of Pharmacology 164 1400-1409. (doi:10.1111/j.14765381.2011.01437.x)

Yang Y, Pei X, Jin Y, Wang Y \& Zhang C 2015 The roles of endoplasmic reticulum stress response in female mammalian reproduction. Cell and Tissue Research. In press.

Yildiz D 2004 Comparision of pure nicotine and smokeless tobacco extract induced formation of 8-OH-dG. Toxicology Mechanisms and Methods 14 253-256. (doi:10.1080/15376520490434700)

Yildiz D, Ercal N \& Armstrong DW 1998 Nicotine enantiomers and oxidative stress. Toxicology 130 155-165. (doi:10.1016/S0300-483X (98)00105-X)

Yung HW, Hemberger M, Watson ED, Senner CE, Jones CP, Kaufman RJ, Charnock-Jones DS \& Burton GJ 2012 Endoplasmic reticulum stress disrupts placental morphogenesis: implications for human intrauterine growth restriction. Journal of Pathology 228 554-564. (doi:10.1016/j. biocel.2012.12.007)

Zhu Z, Xu W, Dai J, Chen X, Zhao X, Fang P, Yang F, Tang M, Wang Z, Wang L et al. 2013 The alteration of protein profile induced by cigarette smoking via oxidative stress in mice epididymis. International Journal of Biochemistry \& Cell Biology 45 571-582. (doi:10.1016/j.biocel.2012. 12.007)

Received 25 June 2015

First decision 27 July 2015

Revised manuscript received 16 September 2015

Accepted 2 October 2015 